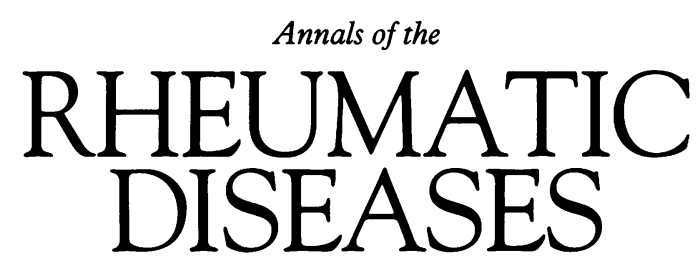

Leader

\title{
Blocking cartilage destruction with metalloproteinase inhibitors: a valid therapeutic target?
}

Conventional treatments for the arthritides do little to affect the underlying disease processes. It is widely accepted that non-steroidal anti-inflammatory drugs only dampen down the inflammatory response and increasingly recognised that the so called disease modifying antirheumatic drugs have little long term effect on disease progression. ${ }^{1}$ New treatments that interfere with specific, critical steps in the pathogenesis of rheumatoid arthritis have been proposed recently and include the prevention of lymphocyte traffic, blocking of cytokine effects, and removal of $\mathrm{T}$ cells with monoclonal antibodies. ${ }^{2}$ Recently, the use of proteinase inhibitors, targeted to prevent the slow and progressive joint destruction seen in many rheumatic diseases, has been proposed as a valid therapeutic approach. $^{3}$

The proteins of cartilage, collagen, and proteoglycan are degraded during joint destruction. Although four main classes of enzymes exist that can break down protein, the matrix metalloproteinases (MMPs) are thought to be responsible for most of this destruction. The MMPs are a potent family of enzymes that, once activated, can destroy all the components of cartilage. ${ }^{4}$ These enzymes have been localised in resorbing cartilage ${ }^{5}$ and shown to be present in rheumatoid and osteoarthritic synovial fluid. ${ }^{6}$ They are normally released from connective tissue cells in an inactive form but can be readily activated by the proteolytic removal of a short peptide. The activated forms are all inhibited by tissue inhibitors of metalloproteinases (TIMPs) that bind very tightly to each activated enzyme and block its action. ${ }^{8}$ In normal tissue there is a balance between the synthesis of the matrix components collagen and proteoglycan and their degradation. Control of the degradative route is determined by the relative amounts of active enzyme and available TIMP. ${ }^{9}$ If TIMP levels exceed those of active enzyme then no breakdown occurs. If local active enzyme levels exceed those of TIMP then uncontrolled degradation will occur until TIMP levels increase.

Consequently, intense research efforts are being made to determine the protein structure of the individual MMPs and TIMPs. ${ }^{1011}$ The long term goal of this research is to discover precisely how TIMPs are able to block the activity of the MMPs, to mimic this action using low molecular weight chemicals, and so develop therapeutic agents that can block the destruction of connective tissue in the rheumatic diseases.
Some progress has been made in designing inhibitors by studying the sequence of amino acids in connective tissue proteins where the MMPs cleave. Medicinal chemists have used chelating agents that bind tightly to the zinc in the active site of the MMP attached to peptides that are recognised by the enzyme (because they mimic the substrate). ${ }^{12}$ Many such potent inhibitors have been produced and can prevent cartilage breakdown in model systems, ${ }^{13}$ corneal ulceration, ${ }^{14}$ tumour metastasis, ${ }^{15}$ and the destruction of cartilage in animal models of arthritis. ${ }^{16}$

But which is the correct MMP to block? Some workers consider that the early loss of proteoglycan from cartilage tissue should be prevented to avoid cartilage damage and that inhibitors targeted to proteoglycan degrading enzymes would be the most useful. Others have proposed that while proteoglycan can be rapidly lost from the tissues, it can also be rapidly replaced, ${ }^{17}$ and the loss of cartilage collagen marks the beginning of irreversible cartilage damage. Consequently, some workers propose that the target enzyme should be collagenase, and inhibitors that are specific for this enzyme should prevent the cartilage destruction seen in the arthritides.

Difficulties do remain. Effective inhibitors must be orally active: as their structures are based on peptide sequences these are often degraded and inactivated by gut peptidases. Although some biostable inhibitors have been synthesised, improvements could still be made. Once the structures of the MMPs and TIMPs are known, and the mechnism of inhibition understood, it should be easier to design structures that are more stable. Some workers are concerned that these compounds will interfere with the normal turnover of connective tissues. It is hoped that the rate of degradation will be slowed in the presence of inhibitors without completely blocking normal turnover.

It will be hard to assess rapidly the effectiveness of these drugs in preventing cartilage loss unless improved techniques are developed to detect cartilage destruction. The current hopes for magnetic resonance imaging are high. Also, if destruction of cartilage is intermittent then it would be very beneficial to have markers that identify those patients that are rapidly degrading cartilage at the time of treatment. These patients could then be recruited into trials of these compounds and should show the maximum benefit. 
Will these compounds work? It is difficult to predict the outcome of the first clinical trials of these new compounds, which should begin within the next year. The results from model systems are encouraging. If the release of connective tissue fragments drives joint inflammation, leading to greater destruction of connective tissue and so causing a chronic cycle of damage, then these compounds could be effective on their own. It may be necessary, however, to combine proteinase inhibitors, either in sequence or together with other agents that hit specific steps in the pathogenesis, before the chronic cycle of joint destruction seen in these diseases can be broken.

Rheumatology Research Unit,

Addenbrooke's Hospital,

T CAWSTON

Hills Road,

Cambridge CB2 2QQ

United Kingdom

1 Kushner I, Dawson N V. Changing perspectives in the treatment of rheumatoid arthritis. 7 Rheumatol 1992; 19: 1831-3.

2 Ziff M. Rheumatoid arthritis its present and future. $\mathcal{f}$ Rheumatol 1990; 17: 127-33.

3 Gordon J L, Drummond A H, Galloway W A. Metalloproteinase inhibitors as therapeutics. Clin Exp Rheumatol 1993; 11 (suppl 8): S91-4.

4 Murphy G, Cawston T E, Galloway W A, et al. Metalloproteinases from rabbit bone culture medium degrade types IV and V collagens, laminin and fibronectin. Biochem f 1981; 199: 807-11.
5 Brinkerhoff C E. Joint destruction in arthritis: metalloproteinases in the spotlight. Arthritis Rheum 1991; 34: 1073-5.

6 Cawston T E, Mercer E, De Silva M, Hazleman B L. Metalloproteinases in rheumatoid synovial fluid. Arthritis Rheum 1984; 27: 285-90.

7 Clark I M, Powell L K, Ramsey S, Hazleman B L, Cawston T E. The measurement of collagenase, TIMP and collagenase-TIMP complex in measurement of collagenase, TIMP and collagenase-TIMP com

8 Cawston T E, Murphy G, Mercer E, Galloway W A, Hazleman B I Reynolds J J. The interaction of purified rabbit bone collagenase with purified rabbit bone metalloproteinase inhibitor. Biochem $\mathcal{F} 1983$; 211 313-8.

9 Cawston T E. The control of connective tissue breakdown-a role fo metalloproteinase inhibitors. Current Medical Literature in Rheumatolog 1984; 3: 127-9.

10 Lloyd L F, Skarzynski T, Wonacott A J, et al. Crystallization and preliminary X-ray analysis of porcine synovial collagenase. $f \mathrm{Mol} \mathrm{Biol} \mathrm{1989;} \mathrm{210:}$ 237-8.

11 Tolley S, Murphy G, O'Shea M, et al. Crystallization and preliminary X-ray analysis of truncated forms of delta 128-194 TIMP-2. $f$ Mol Biol 1993; 229: $1163-4$.

12 Henderson B, Docherty A J P, Beeley N R A. Design of inhibitors of articular cartilage destruction. Drugs of the Future 1990; 15: 495-507.

13 Andrews H J, Plumpton T A, Harper G P, Cawston T E. A synthetic peptide metalloproteinase inhibitor but not TIMP, prevents the breakdown of proteoglycan within articular cartilage in vitro. Agents Actions 1992; 37 $147-54$.

14 Wentworth J S, Paterson C A, Gray R D. Effect of a metalloproteinase inhibitor on established corneal ulcers after an alkali burn. Invest Ophthalmol Vis Sci 1992; 33: 2174-9.

15 Rifkin D B, Tsuboi R Mignatti P. The role of proteases in matrix breakdown during cellular invasion. Am Rev Respir Dis 1989; 140: breakdown

16 DiMartino M J, Wolff C E, High W, Crimmin M J, Galloway W A Antinflammatory and chondroprotective activities of a potent metalloproteinase inhibitor. $\mathcal{F}$ Cell Biochem 1991; suppl 19E: 179.

17 Page-Thomas D P, King B, Stephens T, Dingle J T. In vivo studies of cartilage regeneration after damage induced by catabolin/interleukin-1. Ann Rheum Dis 1991; 50: 75-80. 